\title{
Review
}

nephron

Clinical

Practice

Published online: September 24, 2014

DOI: $10.1159 / 000363704$

\section{Targeting Recovery from Acute Kidney Injury: Incidence and Prevalence of Recovery}

\author{
Etienne Macedo ${ }^{a}$ Ravindra L. Mehta ${ }^{b}$ \\ ${ }^{a}$ Division of Nephrology, University of São Paulo, São Paulo, Brazil; ' ${ }^{\circ}$ Division of Nephrology-Hypertension, \\ School of Medicine, University of California, San Diego, Calif., USA
}

\section{Key Words}

Acute kidney disease - Chronic kidney disease - End-stage renal disease $\cdot$ Renal recovery

\begin{abstract}
Since the creation of Risk, Injury, Failure, Loss of Kidney Function, and End-Stage Renal Disease (RIFLE) criteria in the last 10 years, the use of a standardized definition of acute kidney injury (AKI) has made it possible for epidemiologic studies to document the increasing incidence of AKI, especially in the critical care setting [1]. In addition, several studies applying the criteria of RIFLE, Acute Kidney Injury Network, and, more recently, the Kidney Disease: Improving Global Outcome, were able to establish the association of severity of AKI with adverse clinical outcomes, including the development of chronic kidney disease (CKD) and end-stage renal disease (ESRD) [2-4]. Although, until recently, it was thought that survivors from an AKI episode frequently recover kidney function, cumulative observational data over the past decade have confirmed the association of AKI with the increased risk for permanent kidney damage, with subsequent development of CKD [5]. The epidemiological studies that we will present and discuss in this review confirm and clarify the association of AKI with the development of CKD and ESRD [6-8].

(c) 2014 S. Karger AG, Basel
\end{abstract}

\section{Introduction}

Until recently, patients surviving an episode of acute kidney injury (AKI) were assumed to have a good renal prognosis. This belief was predominantly based on epidemiologic studies that defined renal recovery as dialysis independence at hospital discharge. Although studies from the last decade have confirmed that most survivors from an AKI episode will become independent from renal replacement therapy within 1 year, it has also become clear that a significant number of AKI survivors will develop chronic kidney disease (CKD) and some will progress to end-stage renal disease (ESRD) [5, 8-11].

\section{Definitions of Renal Recovery}

Before the era of Risk, Injury, Failure, Loss of Kidney Function, and End-Stage Renal Disease (RIFLE) and Acute Kidney Injury Network (AKIN) criteria, epidemiologic studies of AKI included heterogeneous populations. Many

Targeting Recovery from Acute Kidney Injury: Round Table Conference at the 19th International Conference on Continuous Renal Replacement Therapies (Manchester Grand Hyatt, San Diego, Calif., USA, March 2-3, 2014).

\section{KARGER}

E-Mail karger@karger.com

www.karger.com/nec
(C) 2014 S. Karger AG, Basel

$1660-2110 / 14 / 1274-0004 \$ 39.50 / 0$
Etienne Macedo

Nephrology Department, University of São Paulo School of Medicine

Av. Dr. Enéas de Carvalho Aguiar, 255, $7^{\circ}$ andar, sala $11 \mathrm{~F}$

São Paulo, SP 05403-000 (Brazil)

E-Mail etimacedo@usp.br 
of these studies included only dialyzed patients. Additionally, different definitions for renal recovery have been used across studies. This lack of a standardized definition for AKI criteria and recovery has determined different prevalence rates of renal recovery in the literature $[5,9,12]$.

A broader criterion for AKI, which is associated with a less specific definition of recovery, determines a high prevalence of renal recovery. Studies including only dialyzed patients and considering recovery as dialysis independence at hospital discharge have shown a high prevalence of renal recovery [13-16]. However, there are critical flaws of these definitions. It is inaccurate to define patients who are dialysis free but have lost $>50 \%$ of their renal function as having 'recovery of renal function'. In addition, excluding patients who were not submitted to dialysis does not account for the increasing proportion of patients who are not dialyzed and have only partial recovery of renal function.

In the last decade, the use of RIFLE and AKIN criteria has determined the inclusion of less severe AKI in epidemiological studies of the syndrome. These studies have helped to strengthen the concept that even mild alterations in renal function can be responsible for increased morbidity and mortality. More attention has been focused on the lack of complete renal recovery after an episode of AKI.

To allow for adequate comparison between studies, the Acute Dialysis Quality Initiative (ADQI) consensus definition also included a definition of renal recovery [1]. Complete recovery is considered a return to a serum creatinine (sCr) $50 \%$ above the baseline level of sCr used for the diagnosis of AKI. Partial renal recovery occurs if the patient does not require chronic dialysis but returns to a $\mathrm{sCr}<50 \%$ from the baseline. Patients who are still dependent on renal replacement therapy after 3 months are considered to have ESRD.

Another parameter that increases the inconsistency among studies is the time to assess renal recovery. Studies focusing on critically ill patients often follow patients for only a short time. In these studies, a significant proportion of patients die before renal recovery as a result of the underlying disease process or of complications associated with AKI. If renal recovery is evaluated including all AKI patients, absence of renal recovery can be overestimated, as a proportion of these patients who died could have had renal recovery if they had survived.

Timing for assessing renal recovery has been inconsistent across studies. Some studies have shown that recovery of renal function can continue after hospital discharge $[17,18]$. The ADQI definition standardizes a minimum

Incidence and Prevalence of AKI Recovery follow-up period of 3 months to determine ESRD and helps to improve generalization across studies. Thus, studies should compare rates of recovery among standardized times, namely intensive care unit or hospital discharge and 90 days after discharge.

\section{Baseline Renal Function to Define Renal Recovery}

In view of the definition of renal recovery, it has become evident that we need to clarify the concept of baseline renal function. Ideally, baseline creatinine should be considered as the last sCr measured in the previous 3-12 months. Since there is no previous assessment of $\mathrm{s} C \mathrm{Cr}$ for a significant proportion of patients, baseline creatinine is often not available. In the absence of a baseline value, most studies consider baseline creatinine as the first measurement at the hospital admission. However, for some patients, this first hospital assessment can reflect a disease process occurring before hospital admission or during the initial phase of hospital care. Patients are often admitted after a period of hypotension, volume depletion, or treatment with a nephrotoxic drug. For these patients, this first creatinine level does not reflect baseline renal function, and this value should not be used to establish renal recovery. In these cases, renal recovery must be evaluated based on the glomerular filtration rate (GFR) calculated by the modification of diet in renal disease (MDRD) equation assuming a normal creatinine for the age, gender and race of the patient. An estimated GFR (eGFR) $>60 \mathrm{ml} / \mathrm{min}$ at hospital discharge or another predefined time could be considered as complete renal recovery. A GFR change $>50 \%$ from the calculated baseline determines a partial renal recovery.

Although this standardization can improve the classification of patients and the comparison across studies, there are still significant flaws. First, depending on the population being studied, a higher proportion of patients with previous renal dysfunction would underestimate recovery. In other words, if patients are mostly elderly and have comorbidities, the use of a normal eGFR would not correspond to the actual renal function, leading to an underestimation of recovery. Secondly, even patients showing complete recovery assessed by sCr can have loss of nephrons and maintain a diminished kidney reserve. As the kidney adapts to the loss of nephrons and the decrease in kidney filtration function can be imperceptible by GFR measurements, a loss of more than half of the function has to occur in order for a filtration marker, such as $\mathrm{sCr}$, to be altered. The loss of the functional kidney reserve is 
one of the reasons why even a complete recovery after an AKI episode can be associated with progression to CKD. The permanent loss of nephrons and the increased risk to develop CKD has been confirmed by epidemiologic studies.

\section{Studies on Epidemiology of Renal Recovery}

\section{Cohorts of Dialyzed Patients}

The prevalence of renal recovery varies depending on the studied population and the definition of renal recovery. Bagshaw et al. [18] evaluated renal recovery in a cohort of 240 critically ill patients who required dialysis. Thirty-two percent of their survivors were on chronic renal replacement at hospital discharge, and $22 \%$ were still on dialysis after 1 year. Bagshaw's cohort included a high percentage of patients with chronic renal dysfunction (45\%) compared with other studies. This high prevalence of CKD was associated with the high incidence of dialysis dependence at hospital discharge.

Schiffl [19] followed 425 critically ill patients with acute tubular necrosis that required dialysis. At hospital discharge, $57 \%$ had normal renal function $(\mathrm{sCr}<1.3 \mathrm{mg}$ / $\mathrm{dl}$ ), $33 \%$ had sCr between 1.3 and $3 \mathrm{mg} / \mathrm{dl}$, and $10 \%$ between 3 and $6 \mathrm{mg} / \mathrm{dl}$. After 1 year of follow up, only 1 patient had progressed to ESRD. In Schiffl's cohort, the higher rates of renal recovery could be attributed to the normal renal function $(\mathrm{sCr}<1.3 \mathrm{mg} / \mathrm{dl}$ or calculated GFR $>90 \mathrm{ml} / \mathrm{min}$ ) of patients before the AKI episode.

Metcalfe et al. [20] found an ESRD incidence of 3\% after 90 days in patients who required dialysis with previous normal renal function and of $16 \%$ in patients with previous renal dysfunction. This study included all AKI hospitalized patients treated with dialysis, not only intensive care unit patients, explaining the lower incidence of ESRD in CKD patients.

\section{Cohorts Including Less Severe AKI}

In 2005, a multinational cohort study, including more than 1,700 critically ill patients across 23 countries with severe but not only dialytic AKI, showed that $13.8 \%$ of survivors required dialysis at hospital discharge [21].

In a prospective study by Lins et al. [22], including 293 patients with previous normal renal function, defining AKI as a creatinine level $>2 \mathrm{mg} / \mathrm{dl}, 9.7 \%$ of survivors had a creatinine clearance $<15 \mathrm{ml} / \mathrm{min}$ at hospital discharge.

In studies including a long-term follow-up, evidence suggests that recovery continues to occur after hospital discharge and peaks between 90 days and 6 months [18,
20, 23-26]. There are few recent studies that followed patients for longer periods of time [25-27].

\section{AKI Defined by RIFLE/AKIN Criteria}

Fewer studies have evaluated patients with less severe AKI. Ali et al. [16] performed a retrospective study using the RIFLE criteria. They found an AKI incidence of 1,811 per million population and of acute on chronic renal failure of 336 per million population. The incidence of ESRD after 90 days was $0.6 \%$ in AKI patients. Renal recovery could not be assessed in $27 \%$ of the patients who died in the acute phase of AKI. Full recovery, defined as creatinine above the threshold level for RIFLE criteria, occurred in $92.5 \%$, and partial recovery in $7 \%$. The incidence of ESRD was higher in patients with previous CKD; $6 \%$ were dialysis dependent after 90 . In these patients, full recovery occurred in $65 \%$ and partial recovery in $29 \%$.

\section{Long-Term Follow-Up}

\section{Progression to CKD}

Since epidemiological studies on AKI show that a considerable number of patients with AKI present only partial renal recovery, AKI is established as an important risk factor for progression to ESRD.

One of the first studies to examine the epidemiology of ESRD and the CKD population was made by Hsu et al. [35]. Using NHANES data (National Health and Nutrition Examination Surveys), they showed that the rise in the incident ESRD overcame the rise in prevalent CKD, which demonstrated that the rise in ESRD is not simply due to an increasing number of CKD patients. An important study by Waikar et al. [36], using Nationwide Inpatient Sample data, showed an increased incidence of AKI between 1988 and 2002, from 61 to 288 per 100,000 population. The annual number of patients who survived acute renal failure requiring dialysis increased from 2.4 to 19.4 per 100,000 population. They estimated that the annual incidence of ESRD from AKI survivors increased from 0.4 to 4.9 per 100,000 population between 1998 and 2002. In the same period, the overall incidence of ESRD in the USA increased from 16 to 34 per 100,000 population [37]. They concluded that the incidence of ESRD attributed to patients who survived an episode of AKI could be as high as a $25 \%$. This percentage could make AKI one of the major causes of ESRD in the USA, similar to diabetes and hypertension (5.2 and 4.8 person-years, respectively) [38]. 
In the last decade, several other studies have supported the concept that AKI is a major risk factor for the development of CKD. Ishani et al. [5] used a 5\% random sample of US Medicare Beneficiary linked to the ESRD incidence database from the US Renal Data System. They found that, in hospitalized patients older than 67 years, AKI was associated with a nearly 7 -fold increase in the development of ESRD during the following 2 years in comparison with patients who did not develop AKI. When stratified on the basis of preexisting CKD, AKI on CKD was associated with a 41-fold increase in the development of ESRD, de novo AKI with a 13 -fold increase, and CKD in the absence of AKI with a nearly 8.5-fold increase in comparison with patients without either AKI or CKD.

Lo et al. [10] evaluated the risk of progressive CKD in a cohort of 556,090 adult patients with baseline eGFR of at least $45 \mathrm{ml} / \mathrm{min} / 1.73 \mathrm{~m}^{2}$ who were hospitalized in Kaiser Permanente of Northern California Health System over an 8-year period. Patients who had dialysis-requiring AKI but were dialysis independent 30 days after hospital discharge had a 28 -fold higher risk of having an eGFR $<30 \mathrm{ml} / \mathrm{min} / 1.73 \mathrm{~m}^{2}$ compared with patients who did not have dialysis-requiring AKI. Dialysis-requiring AKI was also associated with a more than 2-fold increased risk of death.

Similarly, using administrative databases from the Canadian province of Ontario, Wald et al. [28] found an incidence rate of ESRD of 26.3 per 1,000 person-years among 3,769 people who survived an episode of AKI requiring dialysis and were dialysis independent 30 days after hospital discharge compared with an incidence of 9.1 per 1,000 person-years among 13,598 matched controls who did not have AKI, for an adjusted hazard ratio of 3.2. Unlike the previous study, however, Wald et al. [28] did not observe an increase in the long-term mortality risk associated with AKI.

In a cohort of 79,000 inpatients in the Veterans Affairs Medical Center, Amdur et al. [2] evaluated the outcomes of 5,404 patients with the diagnosis of AKI based on ICD9 codes. Patients were excluded from the study if they had preexisting CKD. They showed that patients with AKI were significantly more likely to progress to CKD over a 5-year follow-up period compared to a control group composed of inpatients with myocardial infarction or pneumonia without AKI. Compared to the control group, AKI patients were at higher risk for progressing to CKD stage 4 and had a higher mortality rate.

Bagshaw et al. [18] evaluated the renal function of patients with severe AKI after 1 year of follow-up. The study showed that for patients who recovered, the renal func-

Incidence and Prevalence of AKI Recovery tion after 90 days was similar to the function after 1 year. Morgera et al. [27] evaluated the renal function of 130 AKI patients who required dialysis after an average of 2.5 years. Forty-one percent of their patients developed chronic renal failure and $10 \%$ of them needed chronic dialysis.

Macedo et al. [17] evaluated 84 survivors from an AKI episode who were followed by the same nephrologist for a median of 4.1 years. Renal recovery was defined as GFR $>60 \mathrm{ml} / \mathrm{min} / 1.73 \mathrm{~m}^{2}$. Renal recovery occurred in $16 \mathrm{pa}$ tients $(19 \%)$ at discharge and in $54(64 \%)$ by 18 months. Age and sCr at hospital discharge were independent factors associated with non-renal recovery. AKI severity, evaluated by peak $\mathrm{sCr}$ and need for dialysis, was not associated with non-renal recovery.

Liano et al. [25] evaluated 187 patients who previously presented partial renal recovery after an average period of 7 years. In their study, long-term outcome (assessed by the survival curves) was better among patients who had completely recovered their renal function at hospital discharge than among those with partial recovery. The survival rate was $60 \%$ at 10 years in the complete recovery group and $43 \%$ in the partial recovery group. The factors associated with a worse renal prognosis were $\mathrm{sCr}$ at the time of hospital discharge, age, and presence of comorbidities.

The risk of incomplete recovery and CKD progression increases with the severity of the AKI episode $[6,8]$. Chawla et al. [8] developed a clinical model for risk factors likely to be associated with the progression from AKI to CKD. In 11,589 patients, the severity of AKI was assessed by the maximal increase in $\mathrm{sCr}$ (peak SCr). In multivariable analysis, risk factors for the development of CKD included a diagnosis of acute tubular necrosis (as compared with other etiologies of AKI), need for renal replacement therapy, severity of AKI, serum albumin, and age. The degree of the increase in $\mathrm{sCr}$ was associated with progression to more advanced stages of CKD. Patients who required dialysis had a 500 -fold increase in the risk of subsequent CKD development.

James et al. [30] applied the AKIN criteria in 14,782 patients submitted to coronary angiograms between 2004 and 2006. AKI was diagnosed in 1,099, and progression to AKIN stage 2 or 3 AKI occurred in 321 patients. The adjusted hazard ratio for developing ESRD in patients with AKIN stages 2 or 3 was 11 -fold compared to AKIN stage 1 .

In cardiac surgery patients from the Veterans Affairs Hospitals, Ishani et al. [31] categorized 29,388 patients based on the sCr increase from baseline. They showed a progressive increase in the hazard ratios for incident $\mathrm{CKD}$, progression in CKD stage, and long-term mortal- 
ity across the SCr categories, which demonstrates that an increasing delta $\mathrm{sCr}$ poses an incremental risk for $\mathrm{CDK}$ development.

\section{Conclusion}

In spite of the heterogeneity in study designs, populations, health care systems, and delivery of health care certainly causing contrasting mortality outcomes, these studies substantiate that AKI is associated with CKD development. AKI and CKD could be considered continuums of the same disorder. For epidemiological studies and for clinical practice purposes, AKI episodes should be included as a cause for CKD. Understanding the potential harm resulting from an episode of AKI, clinicians should consider any small increases in sCr as an event to be carefully evaluated. Attention should be given to the growing evidence that the development of AKI has a deleterious long-term effect on the morbidity and mortality of patients. Renal replacement therapy-dependent as well as reversible AKI resulting from nephrotoxic drugs, volume overload, or aggressive diureses might have long-term adverse consequences. Close attention to the drug dose, potential nephrotoxicity, monitoring of the volume status, and accurate recording of hourly urine output are essential in an effort to prevent AKI and all its consequences. Outpatient renal follow-up is fundamental for those patients with previous CKD or for those that do not recover from an AKI episode, as they are at an increased risk for progression to ESRD. Renal recovery must be evaluated no earlier than 1 year after an AKI episode. Nephrology referral should be considered mainly for older patients and those with elevated $\mathrm{sCr}$ at hospital discharge. These practices will help to stop the growing incidence of ESRD derived from AKI episodes.

\section{References}

1 Singbartl K, Kellum JA: AKI in the ICU: definition, epidemiology, risk stratification, and outcomes. Kidney Int 2012;81:819-825.

-2 Amdur RL, Chawla LS, Amodeo S, Kimmel PL, Palant CE: Outcomes following diagnosis of acute renal failure in U.S. veterans: focus on acute tubular necrosis. Kidney Int 2009;76: 1089-1097.

3 Bagshaw SM, George C, Bellomo R: A comparison of the RIFLE and AKIN criteria for acute kidney injury in critically ill patients. Nephrol Dial Transplant 2008;23:1569-1574.

-4 Ali T, Khan I, Simpson W, Prescott G, Townend J, Smith W, Macleod A: Incidence and outcomes in acute kidney injury: a comprehensive population-based study. J Am Soc Nephrol 2007;18:1292-1298.

5 Ishani A, Xue JL, Himmelfarb J, Eggers PW, Kimmel PL, Molitoris BA, Collins AJ: Acute kidney injury increases risk of ESRD among elderly. J Am Soc Nephrol 2009;20:223-228.

-6 Coca SG, Singanamala S, Parikh CR: Chronic kidney disease after acute kidney injury: a systematic review and meta-analysis. Kidney Int 2012;81:442-448.

7 Chawla LS, Kimmel PL: Acute kidney injury and chronic kidney disease: an integrated clinical syndrome. Kidney Int 2012;82:516524.

$\checkmark 8$ Chawla LS, Amdur RL, Amodeo S, Kimmel PL, Palant CE: The severity of acute kidney injury predicts progression to chronic kidney disease. Kidney Int 2011;79:1361-1369.
9 Wald R, Quinn RR, Luo J, Li P, Scales DC, Mamdani MM, Ray JG; University of Toronto Acute Kidney Injury Research Group: Chronic dialysis and death among survivors of acute kidney injury requiring dialysis. JAMA 2009; 302:1179-1185

10 Lo LJ, Go AS, Chertow GM, McCulloch CE, Fan D, Ordoñez JD, Hsu CY: Dialysis-requiring acute renal failure increases the risk of progressive chronic kidney disease. Kidney Int 2009;76:893-899.

11 Lafrance JP, Miller DR: Acute kidney injury associates with increased long-term mortality. J Am Soc Nephrol 2010;21:345-352.

$>12$ Coca SG, Yusuf B, Shlipak MG, Garg AX, Parikh CR: Long-term risk of mortality and other adverse outcomes after acute kidney injury: a systematic review and meta-analysis. Am J Kidney Dis 2009;53:961-973.

13 Augustine JJ, Sandy D, Seifert TH, Paganini EP: A randomized controlled trial comparing intermittent with continuous dialysis in patients with ARF. Am J Kidney Dis 2004;44: 1000-1007.

14 Cosentino F, Chaff C, Piedmonte M: Risk factors influencing survival in ICU acute renal failure. Nephrol Dial Transplant 1994;9 (suppl 4):179-182.

15 Palevsky PM, Zhang JH, O'Connor TZ, Chertow GM, Crowley ST, Choudhury D, Finkel K, Kellum JA, Paganini E, Schein RM, Smith MW, Swanson KM, Thompson BT, Vijayan A, Watnick S, Star RA, Peduzzi P: Intensity of renal support in critically ill patients with acute kidney injury. N Engl J Med 2008;359: $7-20$.
16 Ali T, Khan I, Simpson W, Prescott G, Townend J, Smith W, Macleod A: Incidence and outcomes in acute kidney injury: a comprehensive population-based study. J Am Soc Nephrol 2007;18:1292-1298.

17 Macedo E, Zanetta DMT, Abdulkader RCRM: Long-term follow-up of patients after acute kidney injury: patterns of renal functional recovery. Plos One 2012;7:e36388

18 Bagshaw SM, Laupland KB, Doig CJ, Mortis G, Fick GH, Mucenski M, Godinez-Luna T, Svenson LW, Rosenal T: Prognosis for longterm survival and renal recovery in critically ill patients with severe acute renal failure: a population-based study. Crit Care 2005;9: R700-R709.

19 Schiffl H: Renal recovery from acute tubular necrosis requiring renal replacement therapy: a prospective study in critically ill patients. Nephrol Dial Transplant 2006;21:1248-1252.

20 Metcalfe W, Simpson M, Khan IH, Prescott GJ, Simpson K, Smith WC, MacLeod AM: Acute renal failure requiring renal replacement therapy: incidence and outcome. QJM 2002;95:579-583.

21 Uchino S, Kellum JA, Bellomo R, Doig GS, Morimatsu H, Morgera S, Schetz M, Tan I, Bouman C, Macedo E, Gibney N, Tolwani A, Ronco C: Acute renal failure in critically ill patients: a multinational, multicenter study. JAMA 2005;294:813-818.

22 Lins RL, Elseviers MM, Daelemans R: Severity scoring and mortality 1 year after acute renal failure. Nephrol Dial Transplant 2006;21: 1066-1068. 
23 Kjellstrand CM, Ebben J, Davin T: Time of death, recovery of renal function, development of chronic renal failure and need for chronic hemodialysis in patients with acute tubular necrosis. Trans Am Soc Artif Intern Organs 1981;27:45-50.

24 Hall JW, Johnson WJ, Maher FT, Hunt JC: Immediate and long-term prognosis in acute renal failure. Ann Intern Med 1970;73:515-521.

25 Liano F, Felipe C, Tenorio MT, Rivera M, Abraira V, Saez-de-Urturi JM, Ocana J, Fuentes C, Severiano S: Long-term outcome of acute tubular necrosis: a contribution to its natural history. Kidney Int 2007;71:679-686.

-26 Bell M, Granath F, Schon S, Ekbom A, Martling CR: Continuous renal replacement therapy is associated with less chronic renal failure than intermittent haemodialysis after acute renal failure. Intensive Care Med 2007; 33:773-780.

27 Morgera S, Kraft AK, Siebert G, Luft FC, Neumayer $\mathrm{HH}$ : Long-term outcomes in acute renal failure patients treated with continuous renal replacement therapies. Am J Kidney Dis 2002;40:275-279.

-28 Wald R, Quinn RR, Luo J, Li P, Scales DC, Mamdani MM, Ray JG; University of Toronto Acute Kidney Injury Research Group: Chronic dialysis and death among survivors of acute kidney injury requiring dialysis. JAMA 2009; 302:1179-1185.
9 Palevsky PM: Chronic-on-acute kidney injury. Kidney Int 2012;81:430-431.

30 James MT, Ghali WA, Knudtson ML, Ravani P, Tonelli M, Faris P, Pannu N, Manns BJ, Klarenbach SW, Hemmelgarn BR; Alberta Provincial Project for Outcome Assessment in Coronary Heart Disease (APPROACH) Investigators: Associations between acute kidney injury and cardiovascular and renal outcomes after coronary angiography. Circulation 2011;123:409-416.

31 Ishani A, Nelson D, Clothier B, Schult T, Nugent S, Greer N, Slinin Y, Ensrud KE: The magnitude of acute serum creatinine increase after cardiac surgery and the risk of chronic kidney disease, progression of kidney disease, and death. Arch Intern Med 2011;171:226233.

32 Bellomo R, Cass A, Cole L, Finfer S, Gallagher M, Lo S, McArthur C, McGuinness S, Myburgh J, Norton R, Scheinkestel C, Su S: Intensity of continuous renal-replacement therapy in critically ill patients. N Engl J Med 2009;361:1627-1638.

33 Mehta RL, McDonald B, Gabbai FB, Pahl M, Pascual MT, Farkas A, Kaplan RM: A randomized clinical trial of continuous versus intermittent dialysis for acute renal failure. Kidney Int 2001;60:1154-1163.
34 Vinsonneau C, Camus C, Combes A, Costa de Beauregard MA, Klouche K, Boulain T, Pallot JL, Chiche JD, Taupin P, Landais P, Dhainaut JF: Continuous venovenous haemodiafiltration versus intermittent haemodialysis for acute renal failure in patients with multipleorgan dysfunction syndrome: a multicentre randomised trial. Lancet 2006;368:379-385.

35 Uehlinger DE, Jakob SM, Ferrari P, Eichelberger M, Huynh-Do U, Marti HP, Mohaupt MG, Vogt B, Rothen HU, Regli B, Takala J, Frey FJ: Comparison of continuous and intermittent renal replacement therapy for acute renal failure. Nephrol Dial Transplant 2005; 20:1630-1637.

36 Kumar VA, Yeun JY, Depner TA, Don BR: Extended daily dialysis vs. continuous hemodialysis for ICU patients with acute renal failure: a two-year single center report. Int J Artif Organs 2004;27:371-379.

37 Tonelli M, Manns B, Feller-Kopman D: Acute renal failure in the intensive care unit: a systematic review of the impact of dialytic modality on mortality and renal recovery. Am J Kidney Dis 2002;40:875-885.

38 Rabindranath K, Adams J, Macleod AM, Muirhead N: Intermittent versus continuous renal replacement therapy for acute renal failure in adults. Cochrane Database Syst Rev 2007;3:CD003773. 